УДК 347.7

$10.17213 / 2075-2067-2021-1-32-38$

\title{
ОСОБЕННОСТИ ИНСТИТУТА КОНФЛИКТА ИНТЕРЕСОВ В СФЕРЕ ЗАКУПОК ТОВАРОВ, РАБОТ, УСЛУГ ДЛЯ ОБЕСПЕЧЕНИЯ ГОСУДАРСТВЕННЫХ И МУНИЦИПАЛЬНЫХ НУЖД
}

\author{
(C) 2021 г. T. В. Записная
}

\section{Южно-Российский государственный политехнический университет (НПИ) имени М. И. Платова, г. Новочеркасск, Россия}

Целью статьи является анализ сущности и особенности правоотношений, возникающих в процессе и по поводу разрешения конфликта интересов в контрактной системе государственных закупок.

Методология исследования. Статья базируется на анализе норм российского права, регулирующих правоотношения в контрактной сфере, разъяснений Верховного Суда Российской Федерации, Федеральной антимонопольной службы России, правоприменительной практики, текстов современных теоретиков, позволяющих выявить особенности института конфликта интересов в контрактной сфере.

Результат исследования. $B$ статье предпринята попытка ответить на вопрос об эффективности созданной системы по противодействию коррупщии в сфере закупок, в частности, устранения конфликтов интересов в процессе государственных и муниципальных закупок.

Перспективы исследования. Результаты исследования могут быть использовань правоприменительной деятельностью при выявлении и устранении конфликта интересов в сфере государственных и мунищипальных закупок.

Ключевые слова: конфликт интересов; коррупции; государственная и муниципальная служба; контрактная система; обеспечение государственных и муниципальных нужд; личная заинтересованность; ничтожная сделка; реестр недобросовестных поставщчиков.

\section{FEATURES OF INSTITUTE OF CONFLICT OF INTEREST IN PROCUREMENT OF GOODS, WORKS, SERVICES FOR STATE AND MUNICIPAL NEEDS}

\section{(C) 2021 T. V. Zapisnaya}

\section{Platov South Russian State Polytechnic University (NPI), Novocherkassk, Russia}

The purpose of the article is to analyze the nature and features of legal relations that arise in the process of resolving conflicts of interest in the contract system of public procurement.

Research methodology. The article is based on the analysis of norms of the Russian law governing contractual relations in the field, explanations of the Supreme Court of the Russian Federation, the Federal Antimonopoly service of Russia, enforcement of practices, texts of contemporary theorists, allowing identifying features of Institute of conflict of interests in the contract area. 
Research result. The article attempts to answer the question about the effectiveness of the created system to combat corruption in the field of procurement, in particular, to eliminate conflicts of interest in the process of state and municipal procurement.

Prospects of the study. The results of the study can be used in law enforcement activities to identify and eliminate conflicts of interest in the field of state and municipal procurement.

Key words: conflict of interests; corruption; state and municipal service; contract system; provision of state and municipal needs; personal interest; void transaction; register of unfair suppliers.

Введение. По данным Генеральной Прокуратуры Российской Федерации, ущерб от коррупционных преступлений в России в 2019 году составил около 55,1 млрд. рублей [6]. При всем усилии правоохранительных органов и судов вернуть в бюджет получается незначительную долю средств, выведенных с помощью коррупционных схем. Особенно остро этот вопрос стоит в сфере государственных и муниципальных закупок. Основная задача в области минимизации потерь бюджетных средств лежит в плоскости предупреждения коррупции. Одним из инструментов предупреждения коррупции является институт конфликта интересов.

Правовые основы, регулирующие институт конфликта интересов в сфере закупок. Правовую регламентацию институт конфликта интересов в сфере закупок получил в 2014 году, когда вступил в действие Федеральный закон от 28 декабря 2013 года №396Ф3 «О внесении изменений в отдельные законодательные акты Российской Федерации». Понятие конфликта интересов вплетено в ткань Федерального закона от 5 апреля 2013 года №44-Ф3 «О контрактной системе в сфере закупок товаров, работ, услуг для обеспечения государственных и муниципальных нужд» через требования, предъявляемые к участникам закупки.

Изначально проблема конфликта интересов виделась отечественному законодателю исключительно в рамках государственной и муниципальной службы. Этот вывод можно подтвердить, проследив эволюцию правового регулирования данного института. Однако достаточно быстро стало ясно, что проблема несколько шире. Всевозможные бюджетные учреждения, созданные для исполнения го- сударственных и муниципальных функций в различных областях, активно осваивали бюджетные деньги, причем к чистоте многих сделок у контролирующих органов возникало много вопросов. Этот факт подтолкнул законодателя распространить положения института конфликта интересов на сферу обеспечения государственных и муниципальных нужд.

Институт конфликта интересов устанавливается через разработку и закрепление следующих элементов: определение содержания понятия конфликта интересов, круга субъектов, обязанных выполнять требования по предотвращению и урегулированию конфликта интересов, механизма предотвращения и урегулирования конфликта интересов, правовых последствий несоблюдения требований законодательства по предотвращению и урегулированию конфликта интересов.

При закреплении в законодательстве базового понятия конфликта интересов он определяется как ситуация, при которой личная заинтересованность влияет на принятие решения, также раскрывается понятие личной заинтересованности [1]. Статья 31 Ф3 №44 при определении конфликта интересов указывает на ситуации, при которых он может возникать. Д. Д. Бабаев отмечает, что три вида связей генерируют конфликт интересов: супружеские, кровнородственные и корпоративные (организационные) [5]. В Федеральном законе №44 конфликт интересов и личная заинтересованность разнесены по разным статьям.

Личная заинтересованность определена в п. 22 статьи 34 Ф3 №44 как возможность получения определенными должностными лицами заказчика доходов в виде денег, ценностей, иного имущества, в том числе иму- 
щественных прав или услуг имущественного характера, а также иной выгоды для себя или третьих лиц.

Согласно письму Минтруда России от 26 июля 2018 года №18-0/10/П-5146 [2] при определении оснований для применения взыскания за несоблюдение требований по предотвращению и (или) урегулированию конфликта интересов необходимо установить ряд обстоятельств и в первую очередь наличие личной заинтересованности и ее вида. Следует согласиться с мнением, что понятие «личная заинтересованность» является многосоставным и достаточно сложным для правоприменителя, в том числе членов комиссии по урегулированию конфликта интересов, которые принимают важные решения в отношении служащих [7]. В контексте базового определения конфликта интересов именно наличие личной заинтересованности ставит под вопрос добросовестность исполнения государственным служащим своих обязанностей. Следовательно, в первую очередь необходимо доказать наличие личной заинтересованности, а это в ряде случаев затруднительно.

Круг субъектов, обязанных принимать меры по предотвращению и урегулированию конфликта интересов, законодатель определяет через перечень должностей, при замещении которых возникает соответствующая обязанность. Ф3 №44 в п. 9 части 1 статьи 31 перечисляет субъектов, наличие между которыми супружеской или кровнородственной связи порождает конфликт интересов. Верховный Суд Российской Федерации расширил указанный в законе круг, указав, что конфликт интересов может иметь место не только в отношении руководителей, указанных в пункте 9 части 1 статьи 31 Закона №44-Ф3, но и в отношении должностных лиц (в частности, их заместителей), непосредственно участвующих в осуществлении закупки и полномочия которых являются тождественными по функциональным обязанностям полномочиям руководителя, позволяют влиять на процедуру закупки и результат ее проведения [4].

Федеральный закон №44 сузил перечень ситуаций конфликта интересов по сравнению с Ф3 «О противодействии коррупции». В ходе научных дискуссий не раз поднимался вопрос о целесообразности такого подхо- да законодателя и возможности расширения перечня конфликта интересов в ФЗ №44 [8]. Стоит отметить, что в рамках контрактной системы не предусмотрена как таковая процедура урегулирования конфликта интересов, в рамках которой комиссия по урегулированию конфликта интересов имеет возможность вникнуть во все тонкости сложившейся ситуации и на основании детального разбора сделать вывод о наличии или об отсутствии конфликта интересов. Этот факт в свою очередь и определяет то, что в контрактной сфере не может применяться открытый перечень конфликта интересов. Наличие конфликта интересов является неустранимым препятствием для участия в государственных или муниципальных закупках. Слишком широкое понимание конфликта интересов в контексте Ф3 №44 приведет к правовой неопределенности и нестабильности контрактной системы в случае возникновения множества споров о наличии конфликта интересов в той или иной ситуации.

В первое время поставщики не совсем правильно поняли обязанность по декларированию конфликта интересов. Участники закупок посчитали, что декларировать необходимо наличие конфликта интересов, однако анализ законодательства и позиций Верховного Суда Российской Федерации и Федеральной антимонопольной службы Российской Федерации позволяет сделать однозначный вывод о необходимости декларирования именно отсутствия конфликта интересов. В этом проявляется еще одно отличие института конфликта интересов в контрактной сфере от конфликта интересов государственного или муниципального служащего, потому как последние обязаны декларировать именно наличие возникшего или потенциального конфликта интересов. Декларировать наличие конфликта интересов в контрактной сфере не имеет никакого смысла, данная ситуация блокирует возможность участия в закупке, так как участник автоматически признается не соответствующим требованиям закона. После внесения изменения в российское законодательство в 2019 году и перевода в электронный вид всех закупочных процедур вопрос наличия декларации о конфликте интересов был решен. В настоящее время нельзя миновать 
графу о конфликте интересов при заполнении закупочной документации.

Анализ статей, посвященных правовому регулированию конфликта интересов в контрактной сфере, показывает, что внимание уделяется п. 9 части 1 статьи 31 Ф3 №44 и практически не затрагиваются положения п. 6 статьи 39. Статья 39 устанавливает основы правового положения комиссии по осуществлению закупок. Пункт 6 указанной статьи закрепляет ограничения для физических лиц, при наличии которых они не могут быть членами комиссии. Основным содержанием данных ограничений является то, что членом комиссии по осуществлению закупок не может быть лицо, которое либо имеет личную заинтересованность в результате определения поставщиков, либо на которое может быть оказано влияние со стороны участников закупок. Содержание пункта 6 статьи 39 говорит о конфликте интересов, хотя об этом прямо не написано. В случае выявления в составе комиссии указанных лиц заказчик, принявший решение о создании комиссии, обязан незамедлительно заменить их другими физическими лицами. Комиссия создается до начала закупки, т.е. реально выяснить наличие личной заинтересованности на момент формирования комиссии не представляется возможным, так как еще не известен состав участников закупки. Таким образом, определить присутствие личной заинтересованности членов комиссии заказчика возможно уже только в ходе процедуры закупки. В таком случае возникает вопрос: как должны применяться положения п. 9 части 1 статьи 31 и п. 6 статьи 39 Ф3 №44? Прежде всего, конфликт интересов, определенный п. 9 части 1 статьи 31 , по своему содержанию значительно уже, нежели личная заинтересованность, но имеются и одинаковые положения. В том случае, если участник закупки задекларировал отсутствие конфликта интересов, но реально он имеется в наличии и эта информация стала доступна, то должны применяться положения закона, определяющие правовые последствия несоответствия участника закупки требованиям закона, а также член комиссии должен быть выведен из ее состава. Когда личная заинтересованность не попадает под конфликт интересов, определенный и декла- рируемый в рамках п. 9 части 1 статьи 31 Ф3 №44, то должен применяться п. 6 статьи 39 Ф3 №44, т.е. член комиссии должен быть выведен из ее состава и заменен на другое физическое лицо без правовых последствий для участника закупки.

Руководитель заказчика, члены комиссии по осуществлению закупок, руководитель контрактной службы заказчика, контрактный управляющий могут быть государственными служащими, а могут таковыми и не являться. В том случае, если указанные выше лица являются государственными служащими, возникает вопрос: должны ли применяться положения статей 10 и 11 Ф3 «О противодействии» коррупции? С.Е. Чаннов считает, что ст. 10 и 11 Ф3 «О противодействии коррупции» и нормы Ф3 №44, касающиеся конфликта интересов, в данном случае не являются конкурирующими, следовательно, общее правило о соотношении общей и специальной норм к ним неприменимо [8].

Недействительность государственного или муниципального контракта. В том случае, если контракт был заключен при наличии конфликта интересов, то в силу пункта 2 статьи 168 ГК РФ он является ничтожным, как нарушающий запрет, установленный п. 9 части 1 статьи 31 Закона №44-Ф3, и посягающий на публичные интересы и права третьих лиц. Последствием недействительности государственного и муниципального контракта является двусторонняя реституция. ВС РФ отмечает, что при этом применение двусторонней реституции должно обеспечить возврат в первоначальное положение всех сторон сделки. Возможность применения двусторонней реституции при признании государственного или муниципального контракта по основанию наличия конфликта интересов является, с одной стороны, инструментом предотвращения и возмещения убытков, нанесенных бюджетам всех уровней, с другой стороны - инструментом, сдерживающим участников закупки от нарушения требований закона. Вместе с тем следует признать, что не всегда признание заключенного контракта ничтожным и применение двусторонней реституции является эффективным. В ряде случаев это вызовет большие проблемы, особенно, когда это касается поставок ле- 
карств, медицинского оборудования, ремонта социально значимых объектов.

Следует обратить внимание на п. 1 статьи 167 ГК РФ, согласно ему лицо, которое знало или должно было знать об основаниях недействительности оспоримой сделки, после признания этой сделки недействительной не считается действовавшим добросовестно.

Согласно статье 104 Ф3 №44 в реестр недобросовестных поставщиков включается информация об участниках закупок, уклонившихся от заключения контрактов, а также о поставщиках (подрядчиках, исполнителях), с которыми контракты расторгнуты по решению суда или в случае одностороннего отказа заказчика от исполнения контракта в связи с существенным нарушением ими условий контрактов. В письме от 16 марта 2017 года №ИА/16790/17 [3] ФАС России разъяснил данное положение, указав, что для включения в реестр недобросовестных поставщиков необходимо наличие двух условий в совокупности: 1) поставщиком (подрядчиком, исполнителем) существенно нарушены условия контракта; 2) контракт расторгнут по решению суда. По мнению ФАС России, если контракт расторгнут на основании мирового соглашения между заказчиком и поставщиком (подрядчиком, исполнителем) либо по иным обстоятельствам, не связанным с нарушением поставщиком (подрядчиком, исполнителем) условий контракта, то указанные обстоятельства не являются основанием для включения информации об участнике закупки в Реестр.

Реестр недобросовестных поставщиков является действенным инструментом, дисциплинирующим участников закупок. Потенциал РНП может быть использован при противодействии коррупции в контрактной сфере, если включить признание сделки ничтожной в связи с наличием конфликта интересов как основание для включения в данный реестр.

Заключение. Возникает вопрос: насколько созданный в рамках контрактной системы механизм предотвращения сделок, при заключении которых стороны руководствуются исключительно корыстными интересами, а не государственными, эффек- тивен? Сложность искоренения конфликта интересов из государственных практик состоит в том, что стороны не заинтересованы в раскрытии такой ситуации. Заставить их соблюдать требования закона в части предотвращения конфликта интересов или его урегулирования может либо страх наказания, либо высокий уровень правосознания. Институт конфликта интересов в контрактной сфере - это не только инструмент предупреждения коррупции, но и средство защиты конкуренции.

\section{Литература}

1. Федеральный закон от 25 декабря 2008 г. №273-Ф3 (ред. от 24 апреля 2020 г.) «О противодействии коррупции» // Собрание законодательства РФ. №52 (ч. 1). Ст. 6228. 2008.

2. Письмо Минтруда России от 26.07.2018 г. №18-0/10/П-5146 «О методических рекомендациях по вопросам привлечения к ответственности должностных лиц за непринятие мер по предотвращению и (или) урегулированию конфликта интересов» [Электронный pecypc]. - Режим доступа: https://online3. consultant.ru.

3. Письмо ФАС России от 16 марта 2017 г. №ИА/16790/17 «По вопросам о включении информации в реестр недобросовестных поставщиков» [Электронный ресурс]. — Режим доступа: http://www.consultant.ru.

4. Обзор судебной практики по делам, связанным с разрешением споров о применении п. 9 ч. 1 ст. 31 Федерального закона от 5 апреля 2013 г. №44-Ф3 «О контрактной системе в сфере закупок товаров, работ, услуг для обеспечения государственных и муниципальных нужд» (утв. Президиумом Верховного Суда РФ 28 сентября 2016 г.) // Бюллетень Верховного Суда РФ. - №2. Февраль, 2017.

5. Бабаев Д. Д. Кристаллизация скрытого конфликта в форматах системных злоупотреблений // Гражданское право. - 2020. №1. - C. 37-40.

6. Егоров И. Взятка в особом размере [Электронный ресурс] // Российская газета. 30.03.2020. - Режим доступа: https:// rg.ru/2020/03/30/v-genprokurature-podschitaliushcherb-ot-korrupcii.html. 
7. Уманская В.П., Малеванова Ю.В. Государственное управление и государственная служба в современной России: монография. - Москва: Норма, 2020. - 176 с.

8. Чаннов С.E. Конфликт интересов в сфере закупок для государственных и муниципальных нужд // Гражданин и право. 2016. - №8. - С. 56-65.

\section{References}

1. Federal'nyj zakon ot 25 dekabrja $2008 \mathrm{~g}$. №273-FZ (red. ot 24 aprelja 2020 g.) «O protivodejstvii korrupcii» [Federal Law №273-FZ of December 25, 2008 (as amended on April 24, 2020) «On Combating Corruption»] // Sobranie zakonodatel'stva RF. №52 (part 1). Article 6228. - 2008.

2. Pis'mo Mintruda Rossii ot 26.07.2018 g. №18-0/10/P-5146 «O metodicheskih rekomendacijah po voprosam privlechenija k otvetstvennosti dolzhnostnyh lic za neprinjatie mer po predotvrashheniju i (ili) uregulirovaniju konflikta interesov»» [Letter of the Ministry of Labor of the Russian Federation dated 26.07.2018 №18-0/10/P-5146 «On methodological recommendations on bringing officials to justice for failing to take measures to prevent and (or) resolve conflicts of interests»] [Jelektronnyj resurs]. — URL: https://online3. consultant.ru.

3. Pis'mo FAS Rossii ot 16 marta $2017 \mathrm{~g}$. №IA/16790/17 «Po voprosam o vkljuchenii informacii $\mathrm{v}$ reestr nedobrosovestnyh postavshhikov» [Letter of the FAS of Russia dated March 16, 2017 №IA/16790/17 «On the inclusion of information in the register of unfair suppliers»] [Jelektronnyj resurs]. — URL: http://www.consultant.ru.

4. Obzor sudebnoj praktiki po delam, svjazannym s razresheniem sporov o primene- nii p. 9 ch. 1 st. 31 Federal'nogo zakona ot 5 aprelja 2013 g. №44-FZ «O kontraktnoj sisteme $\mathrm{v}$ sfere zakupok tovarov, rabot, uslug dlja obespechenija gosudarstvennyh i municipal'nyh nuzhd» (utv. Prezidiumom Verhovnogo Suda RF 28 sentjabrja 2016 g.) [Review of judicial practice in cases related to the resolution of disputes on the application of clause 9, Part 1, Article 31 of Federal Law №44-FZ of April 5, 2013 «On the Contract System in the field of Procurement of goods, Works, and services for State and Municipal needs» (approved by the Presidium of the Supreme Court of the Russian Federation on September 28, 2016)] // Bjulleten' Verhovnogo Suda RF. - №2. - February, 2017.

5. Babaev D.D. Kristallizacija skrytogo konflikta $\mathrm{v}$ formatah sistemnyh zloupotreblenij [Crystallization of the hidden conflict in the formats of systemic abuse] // Grazhdanskoe pravo [Civil Law]. — 2020. — №1. Pp. 37-40.

6. Egorov I. Vzjatka v osobom razmere [A bribe in a special size] [Jelektronnyj resurs] // Rossijskaja gazeta. 30.03.2020. — URL: https:// rg.ru/2020/03/30/v-genprokurature-podschitaliushcherb-ot-korrupcii.html.

7. Umanskaja V.P., Malevanova Ju. V. Gosudarstvennoe upravlenie i gosudarstvennaja sluzhba V sovremennoj Rossii: monografija [State management and public service in modern Russia: monograph]. - Moscow: Norma, 2020. - $176 \mathrm{p}$.

8. Channov S.E. Konflikt interesov v sfere zakupok dlja gosudarstvennyh i municipal'nyh nuzhd [Conflict of interests in the field of procurement for state and municipal needs] // Grazhdanin i pravo [Citizen and Law]. - 2016. №8. - P. 56-65. 


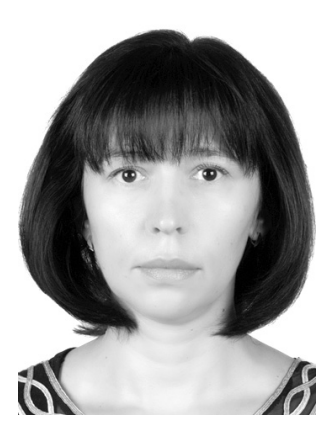

Записная Татьяна Валерьевна - кандидат юридических наук, доцент кафедры «Юриспруденция» Южно-Российского государственного политехнического университета (НПИ) им. М.И. Платова, доцент кафедры «Медицинское право» Ростовского государственного медицинского университета Министерства здравоохранения Российской Федерации.

Zapisnaya Tatiana Valer'evna - Candidate of Juridical Sciences, Assistant Professor of the «Jurisprudence» Department, Platov South-Russian State Polytechnic University (NPI), Assistant Professor of the «Medical law» Department, Rostov State Medical University.

346438, г. Новочеркасск, ул. Просвещения, 132

132 Prosveshcheniya st., 346428. Novocherkassk, Russia E-mail: ztv061@yandex.ru

344022 , г. Ростов-на-Дону, пер. Нахичеванский, 29 29 Nakhichevanskiy av., 344022, Rostov-on-Don, Russia E-mail: ztv061@yandex.ru 